\title{
Discovery of the Gene Encoding a Novel Small Serum Protein (SSP) of Protobothrops flavoviridis and the Evolution of SSPs
}

\author{
Kento Inamaru ${ }^{1}$, Ami Takeuchi ${ }^{1}$, Marie Maeda ${ }^{1}$, Hiroki Shibata ${ }^{2}$, Yasuyuki Fukumaki ${ }^{2}$, \\ Naoko Oda-Ueda ${ }^{3}$, Shosaku Hattori ${ }^{4}$, Motonori Ohno ${ }^{1}$ and Takahito Chijiwa ${ }^{1, *}$ \\ 1 Department of Applied Life Science, Faculty of Bioscience and Biotechnology, Sojo University, \\ Kumamoto 860-0082, Japan; inashimarushi@gmail.com (K.I.); amitakeuchi921@gmail.com (A.M.); \\ yuis2.0603@gmail.com (M.M.); mohno218@ybb.ne.jp (M.O.) \\ 2 Medical Institute of Bioregulation, Research Center of Genetic Information, Kyushu University, \\ Fukuoka 812-8582, Japan; hshibata@gen.kyushu-u.ac.jp (H.S.); yfukumak@gen.kyushu-u.ac.jp (Y.F.) \\ 3 Department of Biochemistry, Faculty of Pharmaceutical Sciences, Sojo University, \\ Kumamoto 860-0082, Japan; naoko@ph.sojo-u.ac.jp \\ 4 Institute of Medical Science, University of Tokyo, Oshima-gun, Kagoshima 894-1531, Japan; \\ shattori@ims.u-tokyo.ac.jp \\ * Correspondence: chijiwa@life.sojo-u.ac.jp; Tel.: +81-96-326-3984
}

Received: 27 January 2020; Accepted: 10 March 2020; Published: 12 March 2020

\begin{abstract}
Small serum proteins (SSPs) are low-molecular-weight proteins in snake serum with affinities for various venom proteins. Five SSPs, PfSSP-1 through PfSSP-5, have been reported in Protobothrops flavoviridis ("habu", Pf) serum so far. Recently, we reported that the five genes encoding these PfSSPs are arranged in tandem on a single chromosome. However, the physiological functions and evolutionary origins of the five SSPs remain poorly understood. In a detailed analysis of the habu draft genome, we found a gene encoding a novel SSP, SSP-6. Structural analysis of the genes encoding SSPs and their genomic arrangement revealed the following: (1) SSP-6 forms a third SSP subgroup; (2) SSP-5 and SSP-6 were present in all snake genomes before the divergence of non-venomous and venomous snakes, while SSP-4 was acquired only by venomous snakes; (3) the composition of paralogous SSP genes in snake genomes seems to reflect snake habitat differences; and (4) the evolutionary emergence of SSP genes is probably related to the physiological functions of SSPs, with an initial snake repertoire of SSP-6 and SSP-5. SSP-4 and its derivative, SSP-3, as well as SSP-1 and SSP-2, appear to be venom-related and were acquired later.
\end{abstract}

Keywords: small serum proteins; Protobothrops flavoviridis; evolution; gene array; comparative genomics

Key Contribution: Discovery of the gene encoding a novel small serum protein (SSP), SSP-6. The proposal of a relationship between the composition of SSP genes and snake habitat conditions. The proposal of a relationship between the evolutionary emergence of SSP genes and the physiological functions of SSPs.

\section{Introduction}

The bites of viperid snakes, including Protobothrops flavoviridis (Pf), cause a variety of symptoms, including bleeding, necrosis, edema, and neurotoxicity, and can be fatal in severe cases. Recent transcriptomic and proteomic studies have identified multiple components of viperid venoms [1-3], including phospholipases $\mathrm{A}_{2}$ [4-7], metalloproteases (snake venom metalloproteases, SVMPs) [8-11], and serine proteases $[12,13]$. Many of these venom proteins have isoforms. In contrast to neurotoxic 
group IA PLA ${ }_{2} \mathrm{~S}$ of elapid (Elapinae and Hydrophiinae) venoms, group IIA-PLA $\mathrm{S}_{2} \mathrm{~s}$ of viperid (Viperinae and Crotalinae) venoms [14], such as hemolytic neutral [Asp $\left.{ }^{49}\right] \mathrm{PLA}_{2} \mathrm{~s}[15,16]$, edema-inducing basic $\left[\mathrm{Asp}^{49}{ }^{4} \mathrm{PLA}_{2} \mathrm{~s}[17,18]\right.$, neurotoxic highly basic [Asp $\left.{ }^{49}\right] \mathrm{PLA}_{2} \mathrm{~s}[19]$, and myotoxic [Lys ${ }^{49}{ }_{\mathrm{PLA}} \mathrm{s}[15,20-22]$, diversified via accelerated evolution, in which nucleotide substitutions occurred predominantly at non-synonymous sites.

In contrast, snakes bitten by themselves or other snakes do not show severe symptoms as humans do. Snake serum is able to neutralize or inhibit snake venom activities. Phospholipase $A_{2}$ inhibitors (PLIs) [23-27] and habu serum factor (HSF) [28,29], which inhibit the hemorrhage induced by SVMPs, are able to neutralize these venom activities. Recently, we found a low-molecular-weight serum protein that specifically binds to myotoxic $\left[\mathrm{Lys}^{49}\right] \mathrm{PLA}_{2}$ isozymes and revealed that this is a homolog of Small Serum Protein-2 (SSP-2), a human prostatic secretory protein superfamily of 94 amino acids (PSP94) [30]. From P. flavoviridis serum, five SSPs, PfSSP-1, PfSSP-2, PfSSP-3, PfSSP-4, and PfSSP-5, have been identified to date [30,31]. However, in terms of blood content, PfSSP-4 and PfSSP- 5 are significantly less abundant than PfSSP-1, PfSSP-2, and PfSSP-3 [31]. SSPs are two-domain proteins [31]. The variable $\mathrm{N}$-terminal domains are thought to be involved in binding diverse target molecules, whereas the C-terminal domain, which is largely conserved among the five SSPs, is assumed to be involved in forming oligomers with HSF [32]. PfSSP-2 and PfSSP-5 show high affinity for triflin, a neurotoxin-like protein that blocks muscle contraction [33,34]. PfSSP-1 and PfSSP-4 show affinity for HV1, a low-molecular-weight SVMP that induces apoptosis of vascular endothelial cells [11,35]. PfSSP-3 binds to flavorase, a non-hemorrhagic SVMP [36]. PfSSP-2 binds to [Lys ${ }^{49}{ }^{\text {PLA }}{ }_{2}$ s [37]. cDNAs encoding five PfSSPs have been isolated and sequenced [30,31]. Interestingly, the cDNAs encoding PfSSP-3 and PfSSP-4 are interrupted by nonsense mutations at the same site on the fourth exon, so as to express truncated mature proteins. The genome fragment containing the genes encoding PfSSP-1 and PfSSP-2 has also been isolated and sequenced [38].

Recently, we revealed that genes for the five PfSSPs, PfSSP-4, PfSSP-5, PfSSP-1, PfSSP-2, and PfSSP-3, are arranged in tandem in this order on one chromosome of P. flavoviridis [39]. According to the configuration of nucleotide sequences in the introns, such as long interspersed nuclear elements (LINEs), DNA transposons, and repetitive sequences, the five PfSSPs can be divided into two subgroups: the Long SSP subgroup consists of PfSSP-1, PfSSP-2, and PfSSP-5, and the Short SSP subgroup consists of PfSSP-3 and PfSSP-4. Mathematical analysis of the nucleotide sequences of PfSSPs showed that PfSSPs in the Short SSP subgroup have evolved in an accelerated manner, whereas those in the Long SSP subgroup have evolved alternately in accelerated and neutral manners. Ortholog analysis of SSP genes from five snakes, including non-venomous snakes, suggested that these genes emerged in the order of their configuration on the chromosome. Moreover, a comparison of the arrays of SSP genes of five snakes showed that the genome segment encompassing SSP-1 to SSP-2 of Protobothrops has been inverted. Chromosome inversion appears to have preserved non-synonymous nucleotide substitutions, providing evidence of accelerated evolution [39].

In the present study, we discovered a gene encoding a novel P. flavoviridis small serum protein, named PfSSP-6, in the $5^{\prime}$ region upstream of the array of five PfSSPs [39]. From a detailed structural analysis, we propose: (1) a novel classification of SSPs, (2) an evolutionary scenario to explain SSP paralogs, (3) a relationship between arrays of SSP paralogs in the snake genome and environmental conditions, (4) relationships between SSP evolution and physiological functions of their products, suggesting an initial repertoire of SSP-6, SSP-5, and SSP-4, and the subsequent appearance of venom-related SSP-1, SSP-2, and SSP-3.

\section{Results and Discussion}

\subsection{Discovery of the Gene Encoding a Novel SSP, PfSSP-6, Far Upstream of the Array of Five PfSSP Genes}

blastn and tblastx analyses of the habu (HabAm1) database [40] using the nucleotide sequence of PfSSP-5 as a query revealed that Scaffold 2858 contains an approximately $3.7 \mathrm{kbp}$ sequence similar 
to the nucleotide sequence of PfSSP-5. The amino acid sequence of its N-terminal domain differs from those of the five known PfSSPs, whereas its C-terminal domain is very similar. Ten cysteines are conserved among PfSSPs. Therefore, this nucleotide sequence was determined to encode a novel type of SSP which was named PfSSP-6. To sequence PfSSP-6, genomic PCR was performed using the draft nucleotide sequence of the corresponding region in Scaffold 2858 of the Amami Island P. flavoviridis genome as a reference. A $1453 \mathrm{bp}$ genome segment that encompassed the $5^{\prime}$ terminus of the putative first exon to the $3^{\prime}$ terminus of the putative third exon of PfSSP-6, and another 2375 bp segment that encompassed the $5^{\prime}$ terminal of the putative third exon to $85 \mathrm{bp}$ downstream from the putative fourth exon of PfSSP- 6 were then acquired. Finally, the 3642 bp sequence of PfSSP- 6 was determined. Referring to the construction of PfSSP-5, definitive exon-intron boundaries of PfSSP-6 were identified. PfSSP-6 consists of four exons and three introns and encodes a 111 amino acid protein, including a 19 amino acid signal peptide. The deduced amino acid sequence of the mature protein encoded by PfSSP-6 shows 33\%-61\% identity with the other five PfSSPs, and the positions of its 10 cysteine residues are conserved (Figure 1). Referring to the draft nucleotide sequence of Scaffold 2858 encompassing PfSSP-6 to PfSSP-4, which is the $5^{\prime}$ terminal gene of the array of five PfSSPs [39], further genomic PCR with the Amami-Oshima P. flavoviridis genome was performed and the 12,406 bp sequence of the intergenic region between PfSSP-6 and PfSSP-4, named PfI-Reg64, was determined (Figure 2).

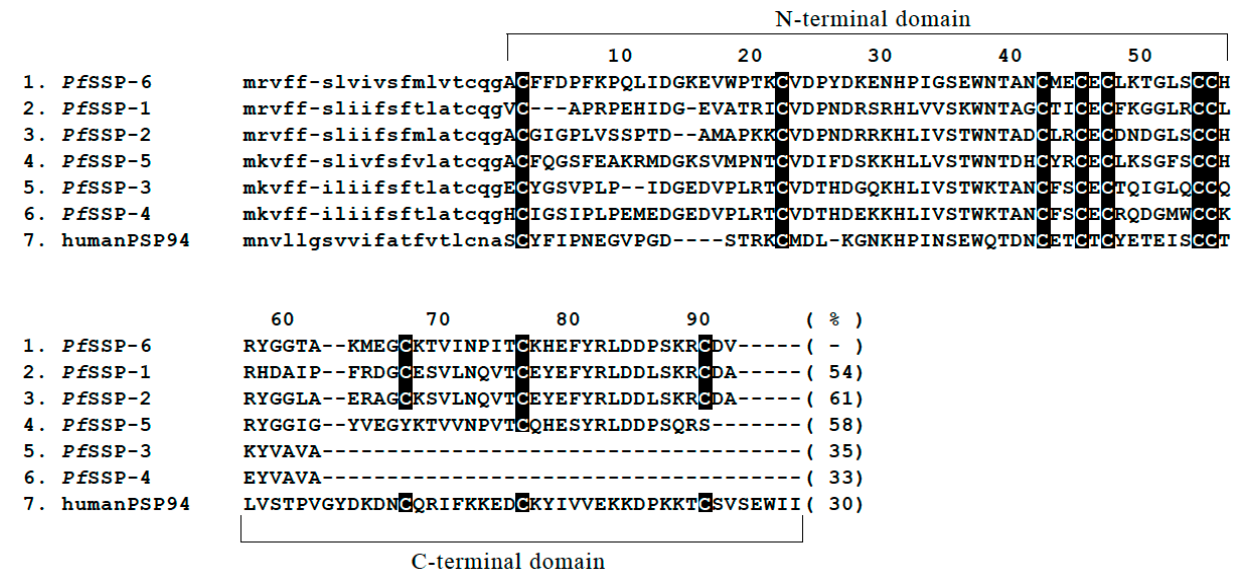

Figure 1. Alignment of the deduced amino acid sequences encoded by the open reading frames (ORFs) of six PfSSPs and human PSP94. Position numbers refer to amino acid residues of the mature proteins. Signal peptide sequences are in lower case letters. The cysteines are shaded. Abbreviations: Pf, P. flavoviridis. References: PfSSP-6 (this study); PfSSP-1 (AB360906.1); PfSSP-2 (AB360907.1); PfSSP-5 (AB360910.1); PfSSP-3 (AB360908.1); PfSSP-4 (AB360909.1) [31]; human PSP94 (NP_002434.1) [41]. Numerals in parentheses show percent identities of PfSSPs and human PSP94 with PfSSP-6.

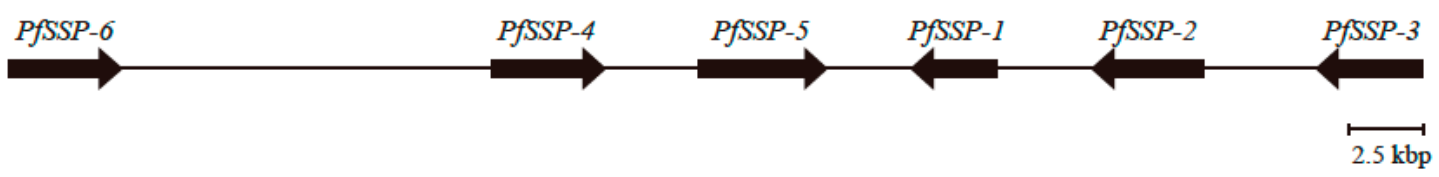

Figure 2. Schematic representation of the 16,048 bp genome segment containing PfSSP-6 in the $5^{\prime}$ region upstream of the array of five PfSSPs. Bold arrows indicate the areas and transcription directions of the genes in the segment.

\subsection{Sequence Configurations Classify the Six PfSSPs Into Three Subgroups}

Introns of PfSSP-6 contained insertions of specific nucleotide sequences, fragments of L1, chicken repeat-1 (CR1), and Gypsy LINEs, fragments of a reverse transcriptase (RT) domain of L2 LINE, fragments of Mariner and hobo-Ac-Tam3 (hAT) DNA transposons, and repetitive sequences, as in the other five PfSSPs (Figure 3). The five inserted fragments, L1 and CR1 LINEs in the first intron and Mariner-iii, Gypsy-i, and Gypsy-ii in the third intron, are conserved in all PfSSPs. These insertions 
must therefore have occurred before the divergence of the six PfSSPs. Second, configurations of the nucleotide sequences inserted into the second or third intron classified the six PfSSPs into two subgroups, Long SSPs and Short SSPs [39]. Long PfSSPs are characterized by the fragment of the RT domain of L2 LINE in the third intron. However, the nucleotide sequence of the fragment of the RT domain of L2 LINE in the third intron of PfSSP- 6 differs from those inserted into the other three genes of conventional Long SSPs, PfSSP-1, PfSSP-2, and PfSSP-5. The fragment of L2 LINE in the third intron of three PfSSPs, PfSSP-1, PfSSP-2, and PfSSP-5, is truncated in the $3^{\prime}$ terminal region (Figure 1). On the other hand, the fragment of L2 LINE in the third intron of PfSSP-6 is truncated from the $5^{\prime}$ terminal region, as in typical LINEs [42]. L2 LINE is composed of two open reading frames, ORF1 and ORF2, in which ORF1 encodes an RNA-binding protein and ORF2 encodes a two-domain protein consisting of an endonuclease (EN) and an RT domain [42]. The RT domain of L2 LINE consists of 10 subdomains numbered from zero to IX and a carboxy-terminal conserved region (CTCR) which is thought to serve as the scaffold of reverse-transcription of L2 LINE [43]. A 320 bp section of the L2 LINE fragment in PfSSP-1 encodes three subdomains, zero to II, of the RT domain. A 431 bp section of that in PfSSP-2 encodes four subdomains, zero to III, of the RT domain, and $1011 \mathrm{bp}$ of the L2 LINE fragment in PfSSP-5 encodes nine subdomains, zero to VIII, of the RT domain [39]. However, $1240 \mathrm{bp}$ of the L2 LINE fragment in PfSSP-6 encode eight subdomains, III to X, and CTCR of the RT domain. This indicates that this L2 LINE is truncated in the $5^{\prime}$ terminal region. It is highly likely that the nucleotide sequence from the $3^{\prime}$ downstream region of the third exon of PfSSP-6 to the $5^{\prime}$ terminal of the inserted L2 LINE fragment of PfSSP- 6 has disappeared, accompanied by $5^{\prime}$ truncation of L2 LINE. These characteristics indicate that PfSSP-6 should be classified as a novel Long SSP. Interestingly, body map analysis using semi-quantitative RT-PCR showed that PfSSP-6 is strongly expressed in the stomach and weakly in the liver (data not shown). It seems that the product of PfSSP-6 is irrelevant to its role in blood. Thus, the three configurations of inserted nucleotide sequences classify the six PfSSPS into three subgroups, conventional and novel Long SSPs, and Short SSPs.

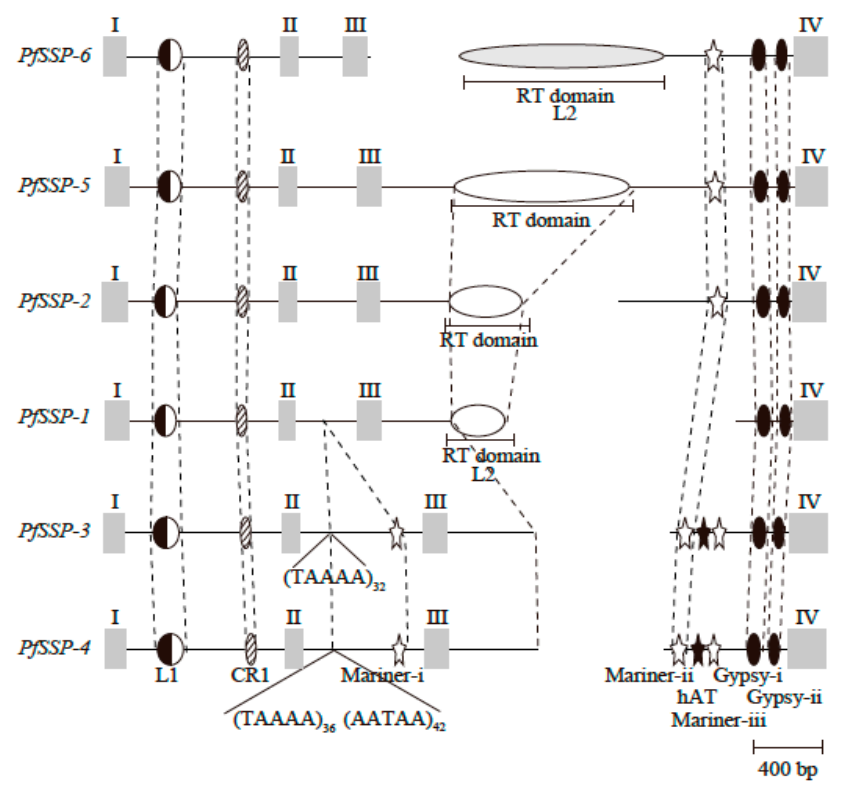

Figure 3. Schematic configurations of nucleotide sequences in the introns of six PfSSPs. Gray bars represent exons. Half-closed, hatched, open, and closed ellipses represent fragments of L1, CR1, L2, and Gypsy LINEs, respectively. Since the fragment of L2 LINE in the third intron of PfSSP-6 differs from those of L2 LINE in the third introns of PfSSP-1, 2, and 5, the ellipse of PfSSP-6 is shown in gray. Open and closed stars represent the fragments of Mariner and hAT DNA transposons. Positions of the corresponding fragments are linked with dashed lines. Positions of repetitive sequences (TAAAA and AATAA) are indicated with carets and numbers of repetitions are indicated as subscripts. 


\subsection{Configurations of SSP Paralogs Relevant to Snake Habitat Conditions}

Following Chijiwa et al. [39], blastn and tblastx analysis of the draft genomes of seven snakes Crotalus viridis (Cv, venomous), Deinagkistrodon acutus (Da, venomous), Ophiophagus hannah (Oh, venomous), Python bivittatus ( $P b$, non-venomous), Protobothrops mucrosquamatus (Pm, venomous), Thamnophis sirtalis (Ts, non-venomous), and Vipera berus (Vb, venomous), in addition to the habu, P. flavoviridis, revealed orthologous relationships and configurations of SSPs (Figure 4). The genome of the non-venomous Burmese python, P. bivittatus (India), contains an ortholog of PfSSP-6, named $P b S S P-6$, and three paralogs of PfSSP-5, named PbSSP- $5 \alpha, P b S S P-5 \beta$, and PbSSP-5 $\gamma(\Psi)$. The genome of the garter snake, T. sirtalis, a North American colubrid, contains an ortholog of PfSSP-6, named TsSSP- 6 , an ortholog of PfSSP-4, called TsSSP-4, and two paralogs of PfSSP-5, TsSSP-5 $\alpha$, and TsSSP-5 $\beta$. The genome of the European adder, $V$. berus, a viperid, contains orthologs of PfSSP-6 and PfSSP-4 in one scaffold (2247), called VbSSP-6 and VbSSP-4 in this study. However, the nucleotide sequences of the second and fourth exons of VbSSP-4 remain unknown. In addition, the ortholog of PfSSP-5, named $V b S S P-5$, was also found in another $V$. berus scaffold $(15,659)$. The genome of the prairie rattlesnake, C. viridis, (North America) possesses orthologs of PfSSP-6, PfSSP-4, and PfSSP-5 on Chromosome 9, named CvSSP-6, CvSSP-4, and CvSSP-5 in this study. The genome of the king cobra, O. hannah, (India) has orthologs of PfSSP-6 and PfSSP-4, named OhSSP-6 and OhSSP-4(Y), and three paralogs of PfSSP-5, named OhSSP-5 $\alpha$, OhSSP-5 $\beta$, and OhSSP-5 $\gamma$ in one scaffold (4527). One ortholog and two paralogs of OhSSPs were renamed in this study. Two nucleotide segments, previously annotated as OhSSP-1 and OhSSP-2 [39], were acquired via genomic PCR to determine their nucleotide sequences. Their nucleotide and deduced amino acid sequences revealed that they are paralogs of PfSSP-5 and should be renamed OhSSP-5 $\beta$ and OhSSP-5 $\gamma$. Therefore, the nucleotide sequence, already annotated as OhSSP-5( $\Psi$ ) [39], was also renamed OhSSP-5 $\alpha$. Structural analysis of the L2 LINE fragment in the third intron showed that $S S P-1, S S P-2$, and SSP-5 belong to the conventional Long SSP subgroup. In addition, the locations of those alleles also suggested that $O h S S P-5 \beta$ and $O h S S P-5 \gamma$ are evolutionarily related to SSP-1 and SSP-2 in D. acutus, P. mucrosquamatus, and P. flavoviridis. The genome of the hundred-pace viper, D. acutus, (Southeast Asia) contained orthologs PfSSP-6, PfSSP-4, PfSSP-1, PfSSP-2, and PfSSP-3 in one scaffold (405), named DaSSP-6, DaSSP-4, DaSSP-1, DaSSP-2, and DaSSP-3 in this study. Only the nucleotide segment corresponding to the second exon of the ortholog of DaSSP-5 was found in the intergenic region between DaSSP-4 and DaSSP-1. Therefore, this fragmented DaSSP-5 is described as $\operatorname{DaSSP}-5 \delta(\Psi)$ in Figure 4. The genome of the Taiwan habu, P. mucrosquamatus, (Taiwan) contained an ortholog of PfSSP-6, named PmSSP-6, and orthologs of PfSSP-5, PfSSP-1, PfSSP-2, and PfSSP-3 in one scaffold (462), named PmSSP-5, PmSSP-1, PmSSP-2, and PmSSP-3. In addition, an ortholog of PfSSP-4, named PmSSP-4, was also found in another scaffold $(21,362)$. Orthologs of PfSSP-6 are conserved in the genomes of all eight snakes, whether venomous or non-venomous. Chijiwa et al. showed that SSP-5 and SSP-4 were the initial genes in the conventional Long and Short SSP subgroups, respectively [39]. Moreover, the current study revealed that the initial repertoire of SSP genes in the genomes of all snakes should be two genes, encoding SSP-6 for the novel Long SSP subgroup and SSP-5 for the conventional Long SSP subgroup, and that the gene encoding SSP-4 was acquired specifically in the genomes of venomous snakes.

Configurations of SSP paralogs in each snake genome were used to classify the eight snakes into three groups. Non-venomous $P$. bivittatus formed the first group, in which two genes encoding SSP-6 and SSP-5 were present in the genome. T. sirtalis, V. berus, C. viridis, and O. hannah formed a second group in which three genes encoding SSP-6, SSP-5, and SSP-4 were present. D. actus, P. mucrosquamatus, and $P$. flavoviridis formed a third group with two genes encoding SSP-1 and SSP-2, in addition to the initial three genes, SSP-6, SSP-4, and SSP-5. This result suggests that the configuration of SSP paralogs is relevant to habitat characteristics of each snake. Snakes in the third group, D. actus, P. mucrosquamatus, and P. flavoviridis, inhabit the Orient, where the warm and humid climate might provide richer and more diversified prey than in Europe and America. It is likely that their venom proteins have become varied, and that the serum proteins that neutralize those venoms then also diversified. O. hannah did 
not need to develop novel varieties of IIA-PLA 2 isozymes; it had another type of venom PLA 2 , the neurotoxic IA-PLA 2 , a lethal component. Therefore, OhSSP-5 $\beta$ and OhSSP-5 $\gamma$, corresponding to $S S P-1$ and/or $S S P-2$, may have had no need to become derivatives as the counterpart of variable IIA-PLA ${ }_{2}$.

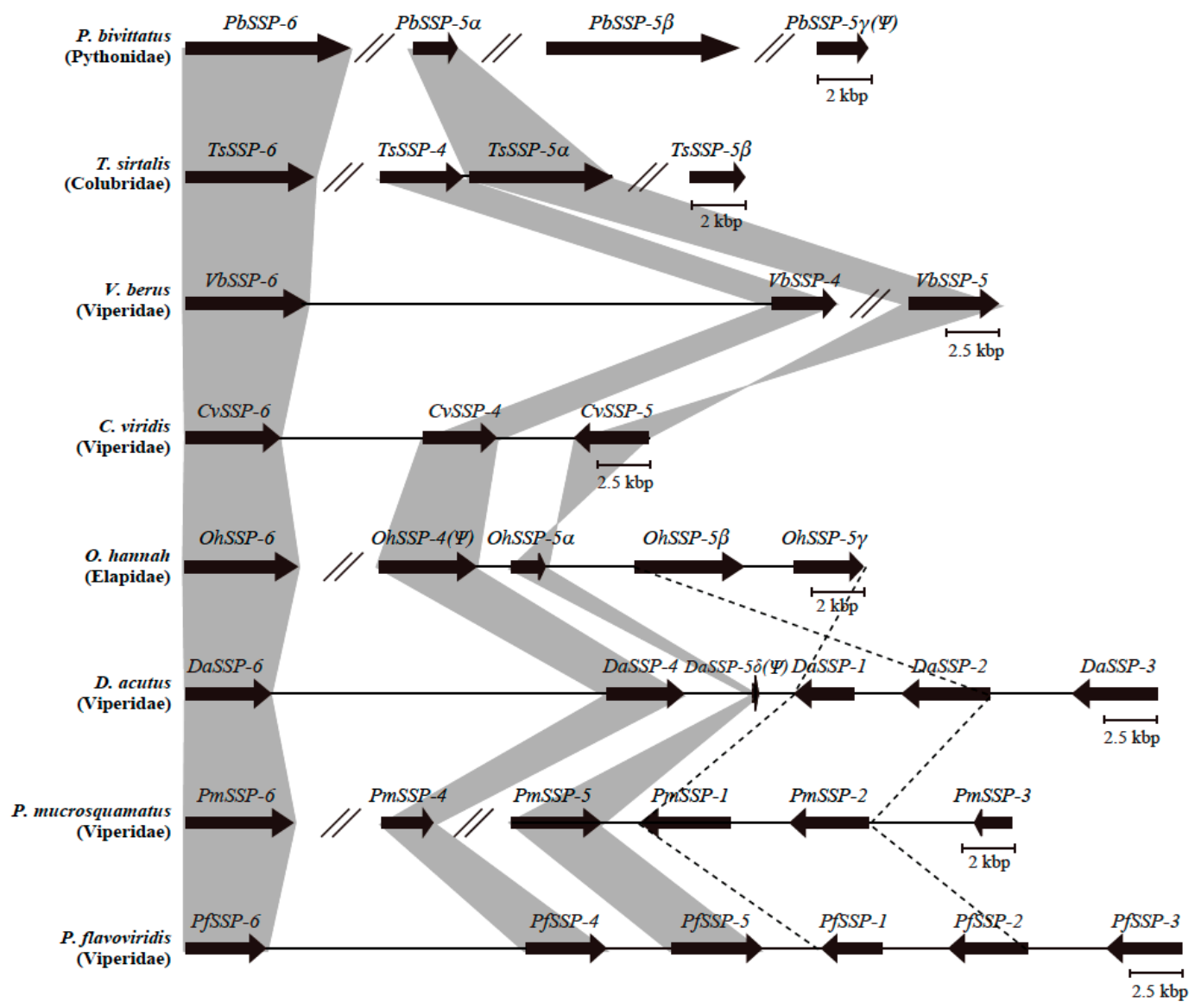

Figure 4. Schematic comparison of the arrays of SSPs of eight snake taxa. Abbreviations: Cv: C. viridis; Da: D. acutus; Oh: O. hannah; Pb: P. bivittatus; Pf: P. flavoviridis; Pm: P. mucrosquamatus; Ts: T. sirtalis; Vb: $V$. berus. Bold arrows indicate the areas and transcription directions of the genes. Orthologs of SSP-6, $S S P-5$, and SSP-4 in each snake genome are linked with gray. Inverted genome segments of $O$. hannah, D. acutus, P. mucrosquamatus, and P. flavoviridis are linked with dashed lines. Double slashes indicate interruptions of the nucleotide sequences.

\subsection{Diversified SSPs Acquired by Advanced Snakes Have More Complex Venom Compositions}

Genes encoding SSP paralogs of each snake were analyzed mathematically. The $K_{\mathrm{A}} / K_{\mathrm{S}}$ ratio, which is the relative ratio of synonymous to nonsynonymous substitutions between the ORFs (Tables 1-8), or $K_{\mathrm{N}}$, which is the rate of substituted nucleotides between the introns, were calculated (Tables 9-13). However, for genes for which full-length nucleotide sequences of exons or introns remained unknown,

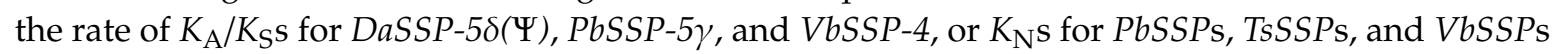
were not calculated. In the previous section, we proposed that the initial repertoire of SSPS in the genomes of venomous snakes comprised SSP-6, SSP-5, and SSP-4. Our mathematical analysis suggested that these three differ in their characteristics. For any snake, the $K_{\mathrm{A}} / K_{\mathrm{S}}$ ratio estimated between the ORFs of SSP- 6 and SSP-5 was the lowest, or considerably lower than the $K_{\mathrm{A}} / K_{\mathrm{S}}$ ratios estimated between other paralogs. On the other hand, the $K_{\mathrm{A}} / K_{\mathrm{S}}$ ratios estimated between $S S P-6$ and SSP-4 and between SSP-5 and SSP-4 were close to one. Our interpretation of these results is as follows. SSP-6 or SSP-5 are irrelevant for neutralizing venom proteins and have constitutive or essential roles, such as digestion or blood homeostasis. Therefore, nucleotide sequences of SSP- 6 and SSP-5 have been 
conserved. On the other hand, $S S P-4$, acquired in the genomes of venomous snakes, may have encoded the first SSP with a role specific to venom neutralization in the event of accidental bites. Therefore, $S S P-4$ may have had to be more plastic than SSP-5 and SSP-6.

Table 1. $K_{\mathrm{A}} / K_{\mathrm{S}}$ ratios estimated between the ORFs of $C$. viridis SSPS.

\begin{tabular}{cccc}
\hline & CvSSP-4 & CvSSP-5 & CvSSP-6 \\
\hline CvSSP-4 & & 0.749 & 0.879 \\
CvSSP-5 & & & 0.306 \\
CvSSP-6 & & & \\
\hline
\end{tabular}

Table 2. $K_{\mathrm{A}} / K_{\mathrm{S}}$ ratios estimated between the ORFs of D. acutus SSPs.

\begin{tabular}{|c|c|c|c|c|c|}
\hline & DaSSP-1 & DaSSP-2 & DaSSP-3 & DaSSP-4 & DaSSP-6 \\
\hline DaSSP-1 & & 1.61 & 0.934 & 0.823 & 0.832 \\
\hline DaSSP-2 & & & 0.849 & 0.705 & 1.03 \\
\hline DaSSP-3 & & & & 1.77 & 0.878 \\
\hline DaSSP-4 & & & & & 0.830 \\
\hline DaSSP-6 & & & & & \\
\hline
\end{tabular}

Table 3. $K_{\mathrm{A}} / K_{\mathrm{S}}$ ratios estimated between the ORFs of O. hannah SSPs.

\begin{tabular}{|c|c|c|c|c|}
\hline 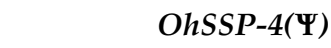 & $O h S S P-5 \alpha$ & $O h S S P-5 \beta$ & $O h S S P-5 \gamma$ & OhSSP-6 \\
\hline 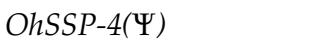 & 0.931 & 0.875 & 0.700 & 0.919 \\
\hline OhSSP-5 $\alpha$ & & 0.836 & 0.719 & 0.666 \\
\hline OhSSP-5 $\beta$ & & & 0.832 & 0.685 \\
\hline OhSSP-5y & & & & 0.509 \\
\hline OhSSP-6 & & & & \\
\hline
\end{tabular}

Table 4. $K_{\mathrm{A}} / K_{\mathrm{S}}$ ratios estimated between the ORFs of P. bivittatus SSPs.

\begin{tabular}{cccc}
\hline & PfSSP-5 $\boldsymbol{\alpha}$ & PfSSP-5 $\boldsymbol{\beta}$ & PbSSP-6 \\
\hline$P b S S P-5 \alpha$ & 1.594 & 0.343 \\
$P b S S P-5 \beta$ & & 0.296 \\
$P b S S P-6$ & & \\
\hline
\end{tabular}

Table $5 . K_{\mathrm{A}} / K_{\mathrm{S}}$ ratios estimated between the ORFs of $P$. mucrosquamatus SSPs.

\begin{tabular}{lccccc}
\hline PmSSP-1 & PmSSP-2 & PmSSP-3 & PmSSP-4 & PmSSP-5 & PmSSP-6 \\
\hline PmSSP-1 & 1.49 & 0.891 & 0.821 & 0.639 & 0.694 \\
PmSSP-2 & & 0.825 & 0.662 & 0.476 & 0.620 \\
PmSSP-3 & & 1.35 & 0.479 & 0.780 \\
PmSSP-4 & & & 0.586 & 0.889 \\
PmSSP-5 & & & & 0.370 \\
PmSSP-6 & & & & \\
\hline
\end{tabular}

Table 6. $K_{\mathrm{A}} / K_{\mathrm{S}}$ ratios estimated between the ORFs of $P$. flavoviridis SSPs.

\begin{tabular}{|c|c|c|c|c|c|}
\hline PfSSP-1 & PfSSP-2 & PfSSP-3 & PfSSP-4 & PfSSP-5 & PfSSP-6 \\
\hline PfSSP-1 & 1.80 & 0.660 & 0.790 & 0.597 & 0.792 \\
\hline PfSSP-2 & & 0.808 & 0.781 & 0.504 & 0.891 \\
\hline PfSSP-3 & & & 1.40 & 0.599 & 0.990 \\
\hline PfSSP-4 & & & & 0.670 & 1.07 \\
\hline PfSSP-5 & & & & & 0.626 \\
\hline PfSSP-6 & & & & & \\
\hline
\end{tabular}


Table 7. $K_{\mathrm{A}} / K_{\mathrm{S}}$ ratios estimated between the ORFs of T. sirtalis SSPS.

\begin{tabular}{ccccc}
\hline & TsSSP-4 & TsSSP-5 $\alpha$ & TsSSP-5 $\beta$ & TsSSP-6 \\
\hline TsSSP-4 & 1.06 & 0.603 & 0.651 \\
TsSSP-5 $\alpha$ & & 0.675 & 0.447 \\
TsSSP-5 $\beta$ & & & 0.659 \\
TsSSP-6 & & & \\
\hline
\end{tabular}

Table 8. $K_{\mathrm{A}} / K_{\mathrm{S}}$ ratios estimated between the ORFs of $V$. berus SSPs.

\begin{tabular}{lcc}
\hline & VbSSP-5 & VbSSP-6 \\
\hline$V b S S P-5$ & 0.604 \\
$V b S S P-6$ & \\
\hline
\end{tabular}

Table 9. $K_{\mathrm{N}}$ values estimated between the introns of C. viridis SSPs.

\begin{tabular}{cccc}
\hline & CvSSP-4 & CvSSP-5 & CvSSP-6 \\
\hline CvSSP-4 & & 0.319 & 0.358 \\
CvSSP-5 & & & 0.372 \\
CvSSP-6 & & & \\
\hline
\end{tabular}

Table 10. $K_{\mathrm{N}}$ values estimated between the introns of D. acutus SSPs.

\begin{tabular}{|c|c|c|c|c|c|}
\hline & DaSSP-1 & DaSSP-2 & DaSSP-3 & DaSSP-4 & DaSSP-6 \\
\hline DaSSP-1 & & 0.0227 & 0.248 & 0.253 & 0.249 \\
\hline DaSSP-2 & & & 0.247 & 0.251 & 0.246 \\
\hline DaSSP-3 & & & & 0.0050 & 0.285 \\
\hline DaSSP-4 & & & & & 0.288 \\
\hline DaSSP-6 & & & & & \\
\hline
\end{tabular}

Table 11. $K_{\mathrm{N}}$ values estimated between the introns of $O$. hannah SSPs.

\begin{tabular}{|c|c|c|c|c|c|}
\hline & 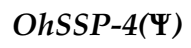 & OhSSP-5a & $O h S S P-5 \beta$ & $O h S S P-5 \gamma$ & OhSSP-6 \\
\hline$O h S S P-4(\Psi)$ & & 0.331 & 0.340 & 0.324 & 0.530 \\
\hline OhSSP-5 $\alpha$ & & & 0.0615 & 0.0801 & 0.277 \\
\hline$O h S S P-5 \beta$ & & & & 0.0857 & 0.226 \\
\hline OhSSP-5y & & & & & 0.275 \\
\hline OhSSP-6 & & & & & \\
\hline
\end{tabular}

Table 12. $K_{\mathrm{N}}$ values estimated between the introns of P. mucrosquamatus SSPs.

\begin{tabular}{lcccccc}
\hline & PmSSP-1 & PmSSP-2 & PmSSP-3 & PmSSP-4 & PmSSP-5 & PmSSP-6 \\
\hline PmSSP-1 & 0.154 & 0.338 & 0.342 & 0.339 & 0.374 \\
PmSSP-2 & & 0.281 & 0.284 & 0.262 & 0.316 \\
PmSSP-3 & & & 0.0397 & 0.293 & 0.346 \\
PmSSP-4 & & & & 0.296 & 0.349 \\
PmSSP-5 & & & & & 0.295 \\
PmSSP-6 & & & & & \\
\hline
\end{tabular}


Table 13. $K_{\mathrm{N}}$ values estimated between the introns of P. flavoviridis SSPs.

\begin{tabular}{lcccccc}
\hline & PfSSP-1 & PfSSP-2 & PfSSP-3 & PfSSP-4 & PfSSP-5 & PfSSP-6 \\
\hline PfSSP-1 & 0.0317 & 0.251 & 0.258 & 0.248 & 0.231 \\
PfSSP-2 & & 0.254 & 0.261 & 0.253 & 0.229 \\
PfSSP-3 & & & 0.0283 & 0.261 & 0.279 \\
PfSSP-4 & & & & 0.270 & 0.287 \\
PfSSP-5 & & & & & 0.267 \\
PfSSP-6 & & & & & \\
\hline
\end{tabular}

The $K_{\mathrm{A}} / K_{\mathrm{S}}$ ratios estimated between DaSSP-1 and DaSSP-2, DaSSP-3 and DaSSP-4, PmSSP-1 and PmSSP-2, PmSSP-3 and PmSSP-4, PfSSP-1 and PfSSP-2, and PfSSP-3 and PfSSP-4 were 1.61, 1.77, 1.49, $1.35,1.80$, and 1.42 , respectively (Table 2, Table 5, and Table 6), and the rates of $K_{N}$ were $0.0227,0.005$, $0.154,0.0397,0.0317$, and 0.0283 , respectively (Table 10, Table 12, and Table 13). These results showed that the branching of these genes, especially late genes such as SSP-1, SSP-2, or SSP-3, occurred in an accelerated manner, and that the time that passed after their divergence was very short. In addition, the $K_{\mathrm{A}} / K_{\mathrm{S}}$ ratios estimated between SSP-1 and SSP- 5 or SSP-2 and SSP-5 of D. acutus, P. mucrosquamatus, and $P$. flavoviridis were around 0.7. This result also supports the idea that SSP-1 or SSP-2 and SSP-5 are evolutionarily related, as suggested above. That is, SSP-1 and SSP-2 were recently derived from SSP-5 and then diversified in an accelerated manner to accommodate venom proteins. SSP-3, the truncated SSP acquired as the successor to SSP-4, is also thought to bind more venom proteins than SSP- 4 , as do SSP- 1 and SSP-2 relative to SSP-5. Therefore, the $K_{\mathrm{A}} / K_{\mathrm{S}}$ ratios estimated between SSP-3 and SSP-4 also show considerably higher values. The many reports that venom proteins bind to SSP-1 [35], SSP-2 [33,37], or SSP-3 [36] also support the above idea. Since animal venoms work as defense mechanisms, as tools to catch prey, or simply to enhance digestion, they should be sensitive to the surrounding environment. Because venom proteins have become more diversified in environments where there are more diverse prey, serum proteins required to neutralize venom activities, such as $S S P-1, S S P-2$, and SSP-3, have also diversified in an accelerated manner. Even among conventional Long SSPs, SSP-1, SSP-2, and SSP-5 have evolved in an accelerated or neutral manner, depending on whether they deal with venom components. On the other hand, SSP-3 and SSP-4, which specifically arose as anti-venom proteins, have evolved in an accelerated manner.

Chijiwa et al. proposed that most nucleotide substitutions at non-synonymous sites occur only immediately after gene duplication. Then random mutations accumulate over time, and selective pressure that leaves "neutral" mutations at synonymous sites erases the traces of accelerated evolution [39]. However, in the genomes of the viperids P. flavoviridis and P. mucrosquamatus, inversion of the genome segment encompassing SSP-1 to SSP-2 occurred, and subsequent accumulation of random mutations was suppressed [39]. These findings are also applicable to D. acutus DaSSP-1 and DaSSP-2. Since the SSP-3 allele is located in the $3^{\prime}$ region downstream of the inverted genome segment containing SSP-1 and SSP-2, the inversion may also have suppressed accumulation of random mutations in PfSSP-3.

\section{Materials and Methods}

\subsection{Materials}

P. flavoviridis specimens were provided by the Institute of Medical Sciences of the University of Tokyo. The tail of an O. hannah specimen was provided by the Japan Snake Center. That of a P. mucrosquamatus was provided by the Medical Institute of Bioregulation, at the Research Center of Genetic Information, Kyushu University. High-molecular-weight genomic DNA was prepared from livers or tails of the snakes according to the method of Blin and Stafford [44]. Total RNA was prepared from various snake organs, according to the ISOGEN protocol (Nippon Gene, Toyama, Japan). Restriction endonucleases and KOD plus DNA polymerase were purchased from Nippon Gene 
and TOYOBO (Osaka, Japan), respectively. Other reagents and antibiotics were from Nacalai Tesque (Kyoto, Japan) and TAKARA BIO (Shiga, Japan). Specific oligonucleotide primers were synthesized by GENNET (Fukuoka, Japan).

\subsection{Cloning and Sequencing of the Genome Segment Containing PfSSP-6}

A dedicated database, HabAm1, [40] was constructed to carry out blastn and tblastx analysis with the nucleotide sequences of PfSSPs (PfSSP-1-PfSSP-5) as queries. Exon-intron boundaries were then determined based on the five PfSSPs. Referring to the nucleotide sequence of Scaffold 2858, the sense primer SSP6-5UTR-1, 5' -ggC gTC CCT CCT TCT CCT Tg-3', which anneals specifically to the first exon of PfSSP-6, and the antisense primer SSP6ex3-2, 5'-CTC gCA TTC CAT ACA ATT ggC Tg- ${ }^{\prime}$, which anneals specifically to the third exon of PfSSP-6, were used to amplify the 1453 bp genome fragment (Table 14). The sense primer, SSP6ex3-1, 5'-TgT ggC CAA CCA AAT gCg Tgg-3', which anneals specifically to the third exon of PfSSP-6, and the antisense primer SSP6-3flank-1, 5'-CAg CTA TgC ATg CCT TAT ATC AC-3', which anneals specifically to $85 \mathrm{bp} 3^{\prime}$ downstream of the fourth exon of PfSSP-6, were then used to amplify the $2363 \mathrm{bp}$ genome fragment (Table 14). Amplified genome fragments were ligated to the $\mathrm{PCR}^{\mathrm{TM}}$-Blunt II-TOPO ${ }^{\circledR}$ vector (Life Technologies, Carlsbad, CA, USA) and transformed with DH5 $\alpha$-competent cells (TAKARA BIO, Shiga, Japan). Nucleotide sequences were determined using an ABI 3130xl capillary sequencer. The $1453 \mathrm{bp}$ PCR fragment overlapped with the $2363 \mathrm{bp}$ PCR fragment by $89 \mathrm{bp}$. The physical structure of the $3727 \mathrm{bp}$ segment encompassing

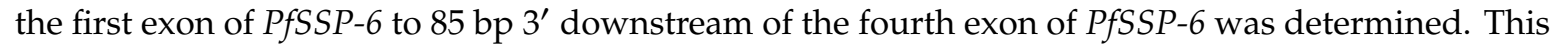
$3727 \mathrm{bp}$ DNA fragment contained four exons encoding PfSSP-6. Moreover, to acquire the nucleotide sequence of the intergenic region between PfSSP-6 and PfSSP-4, named PfI-Reg64, genomic PCR was carried out against the Amami-Oshima P. flavoviridis genome and the sense primer Ireg64-1, 5' $-\mathrm{CTC}$ CAT gCA AAg gAg gAT TTC C- $3^{\prime}$, which anneals to the $3^{\prime}$ terminus of the third intron of PfSSP- 6 , and the antisense primer Ireg64-6, 5'-TAg gCC TTg ACA CAT gAT ggC-3', which anneals to the middle portion of $P f \mathrm{I}$-Reg64, were used to amplify the $7717 \mathrm{bp}$ genome fragment, named $P f I R E G 64-\mathrm{I}$ (Table 14). The PfIREG64-I fragment was also cloned and sequenced. The 7717 bp PfIREG64-I overlapped with the 3727 bp PfSSP-6 by 474 bp. The sense primer Ireg64-5, 5'-CAT TgT TgA gCA ACC CTT ggC-3', which anneals $2501 \mathrm{bp} 5^{\prime}$ upstream of Ireg64-6, and the antisense primer Ireg64-8 5'-ggA CTA TTA AgC AgT ggA ATg gC- $3^{\prime}$, which anneals 2340 bp $5^{\prime}$ upstream of the first exon of PfSSP-4 ( $3^{\prime}$ terminal of PfIReg-64), were then used to amplify the 5283 bp genome fragment, named PfIREG64-II (Table 14). The PfIREG64-II fragment was also cloned and sequenced. The 5283 bp PfIREG64-II overlapped with the 7717 bp PfIREG64-I by 2523 bp. The sense primer Ireg64-9, 5' -ggC CCT CTT CCA Agg ACA $\mathrm{AgC}-3^{\prime}$, which anneals $455 \mathrm{bp} 5^{\prime}$ upstream of Ireg64-8, and the antisense primer Ireg64-10, $5^{\prime}$-ACC TCg TTC CTC CAg CCA CT- $3^{\prime}$, which anneals to the $5^{\prime}$ terminus of the first intron of PfSSP-4, were then used the 2971 bp genome fragment, named PfIREG64-III (Table 14). The PfIREG64-III fragment was also cloned and sequenced. The 2971 bp PfIREG64-III overlapped with the 5267 bp PfIREG64-II by 455 bp. Finally, the physical structure of the 16,248 bp segment encompassing the third intron of PfSSP- 6 to the first intron of PfSSP-4 was completely established. The nucleotide sequences of PfSSP- 6 and the genome segment from PfSSP-6 to PfSSP-4 are available from the Genbank/EMBL/DDBJ databases under Accession No. LC518073. 
Table 14. Primers used to acquire the nucleotide sequences from the genome domain encompassing PfSSP-6 to PfSSP-4. The symbols (f) or (r) after the position numbers indicate the directions of the primers. Forward or reverse denote whether the direction of elongation was the same or opposite to that of transcription. Nucleotide positions refer to nucleotide sequences reported in this study (LC518073).

\begin{tabular}{|c|c|c|}
\hline Name & Positions & Nucleotide Sequence (GC Content: \%, Tm: ${ }^{\circ} \mathrm{C}$ ) \\
\hline SSP6-5UTR-1 & $1-20(f)$ & $5^{\prime}-$ ggC gTC ССТ ССТ ТСТ ССТ Tg -3' $(65,66)$ \\
\hline SSP6ex3-2 & $1431-1453(r)$ & $5^{\prime}-$ CTC gCA TTC CAT ACA ATT ggC Tg-3' $(48,68)$ \\
\hline SSP6ex3-1 & $1365-1385$ (f) & $5^{\prime}-\mathrm{TgT}$ ggC CAA CCA AAT gCg Tgg $-3^{\prime}(57,66)$ \\
\hline SSP6-3UTR-2 & $3581-3604(r)$ & 5' - ACA TgA gAg ATT TAT TCC AgT gTg-3' $(38,66)$ \\
\hline SSP6-3flank-1 & $3705-3727(r)$ & $5^{\prime}-$ CAg CTA TgC ATg CCT TAT ATC AC $-3^{\prime}(43,66)$ \\
\hline Ireg64-1 & $3254-3275$ (f) & 5' - CTC CAT gCA AAg gAg gAT TTC C -3' $(50,66)$ \\
\hline Ireg64-6 & $10,950-10,970(r)$ & $5^{\prime}-\mathrm{TAg}$ gCC TTg ACA CAT gAT ggC $-3^{\prime}(52,64)$ \\
\hline Ireg64-5 & $8449-8469$ (f) & $5^{\prime}-$ CAT TgT TgA gCA ACC CTT ggC - $3^{\prime}(52,64)$ \\
\hline Ireg64-8 & $13,709-13,731(\mathrm{r})$ & $5^{\prime}$ - ggA CTA TTA AgC AgT ggA ATg gC -3' $(48,68)$ \\
\hline Ireg64-9 & $13,277-13,297$ (f) & $5^{\prime}-\operatorname{ggC}$ CСТ CTT CCA Agg ACA AgC -3' $(62,68)$ \\
\hline Ireg64-10 & $16,228-16,247(\mathrm{r})$ & $5^{\prime}-$ ACC TCg TTC CTC CAg CCA CT -3' $(60,64)$ \\
\hline
\end{tabular}

\subsection{RepeatMasker Analysis of the Nucleotide Sequence of PfSSP-6}

A dedicated database was constructed with repetitive sequences of the genomes of various organisms collected from Repbase of the Genetic Information Research Institute [45]. RepeatMasker utilized the nucleotide sequences of PfSSP-6 against the database via BLAST+, RMBlast (NCBI), and Tandem Repeats Finder (Boston University) [46].

3.4. Determination of Nucleotide Sequences and Chromosomal Configurations of Genes Encoding Orthologs of PfSSPs from Seven Snake Taxa

Draft nucleotide sequences of the genomes of seven taxa, C. viridis (Cv, venomous) [47], D. acutus (Da, venomous) [48], O. hannah (Oh, venomous) [49], P. bivittatus (Pb, non-venomous) [50], P. mucrosquamatus (Pm, venomous) [51], T. sirtalis (Ts, non-venomous) [52], and V. berus (Vb, venomous) [53], were downloaded to create a dedicated genome database. Referring to the nucleotide and amino acid sequences of PfSSPs deduced using tblastn or blastn, the nucleotide sequences encoding orthologs of PfSSPs and their flanking regions in each snake genome were ascertained. The T. sirtalis genome segment containing TsSSP-4 and TsSSP-5 $\alpha$ and the three P. bivittatus genes, PbSSP-5 $\alpha, P b S S P-5 \beta$, and $P b S S P-5 \gamma(\Psi)$, were identified in separate scaffolds; therefore, their locations and arrangements are tentative.

\subsection{Determining the Nucleotide Sequences of SSP Paralogs of P. mucrosquamatus and O. hannah}

To acquire complete nucleotide sequences of PmSSP-3, PmSSP-4, OhSSP-1, OhSSP-2, OhSSP-5, and OhSSP-6, genomic PCR was performed on the O. hannah and P. mucrosquamatus genomes to amplify two overlapping nucleotide segments separately. These included the $5^{\prime}$ segment of the gene encompassing the first exon to the second exon, and the $3^{\prime}$ segment of the gene encompassing the second exon to the fourth exon of each gene.

For PmSSP-3 (Pm Scaffold 462), the sense primer, PmSSP34-5UTR, 5' -CAA ggg TTg gTC TTg gTT TTT g- $3^{\prime}$, which anneals to the $5^{\prime}$ terminus of the first exon of PmSSP-3 and PmSSP-4, and the antisense primer, PmSSP3ex2-R, 5' -ggT AgA gAA AAg CCC CCA AAg-3', which anneals to the second exon of PmSSP-3, were used to amplify the $1169 \mathrm{bp} \mathrm{5'}$ segment of PmSSP-3 (Table 15). The sense primer, PmSSP3-F, 5'-TgC TTT ggg ggC TTT TCT C-3' , which anneals to the middle portion of the second exon of PmSSP-3, and the antisense primer, PmSSP34-R, 5' -CTT gAC TgA GAC TgA AgT TCC-3', which anneals to the $311 \mathrm{bp} 3^{\prime}$ region downstream of the fourth exon of PmSSP-3 and PmSSP-4, were then used to amplify the $2722 \mathrm{bp} 3^{\prime}$ segment of PmSSP-3 (Table 15). The 5' segment of PmSSP-3 overlapped with the $3^{\prime}$ segment of PmSSP-3 by $31 \mathrm{bp}$. The physical structure of the $3860 \mathrm{bp}$ segment encompassing 
the first exon of PmSSP-3 to the $311 \mathrm{bp}$ at the $3^{\prime}$ region downstream of the fourth exon of $P m S S P-3$ was completed.

Table 15. Primers utilized to determine nucleotide sequences of genome fragments containing SSPs of $P$. mucrosquamatus and O. hannah. The symbols (f) or (r) after the position numbers indicate the directions of the primers. Forward or reverse indicate whether the direction of elongation was the same or opposite to that of transcription. Nucleotide positions refer to the nucleotide sequences reported in this study. Abbreviations: Oh: O. hannah; Pm: P. mucrosquamatus.

\begin{tabular}{|c|c|c|}
\hline Name & Scaffold & Nucleotide Sequence (GC Content: \%, Tm: ${ }^{\circ} \mathrm{C}$ ) \\
\hline PmSSP34-5UTR (f) & Pm Scaffold 462 & 5' - CAA ggg TTg gTC TTg gTT TTT g -3' $(45,64)$ \\
\hline PmSSP3ex2-R (r) & Pm Scaffold 462 & $5^{\prime}$ - ggT AgA gAA AAg CCC CCA AAg -3' $(52,64)$ \\
\hline PmSSP3-F (f) & Pm Scaffold 462 & $5^{\prime}-$ TgC TTT ggg ggC TTT TCT C - $3^{\prime}(47,56)$ \\
\hline PmSSP34-R (r) & Pm Scaffold 462 & $5^{\prime}$ - CTT gAC TgA GAC TgA AgT TCC -3' $(45,62)$ \\
\hline PmSSP4ex2-R (r) & $P m$ Scaffold 462 & $5^{\prime}-$ CgT TTC Agg TAA Agg AAT ACT C -3' $(41,62)$ \\
\hline PmSSP4-F (f) & Pm Scaffold 21,362 & $5^{\prime}$ - gAg TAT TCC TTT ACC TgA AAC g -3' $(41,62)$ \\
\hline OhSSPs-5UTR (f) & Oh Scaffold 4527 & 5' - ATA AAT Tgg Agg AgC RgA TTC CT -3' $(43,66)$ \\
\hline OhSSP5-ex2-R (r) & Oh Scaffold 4527 & 5'- CTC AgC TTC AAA gCC CCA gg -3' $(60,64)$ \\
\hline OhSSP5-F (f) & Oh Scaffold 4527 & $5^{\prime}$ - gAg CAT gCT TTA CCT ggg gC -3' $(60,64)$ \\
\hline OhSSP5-R (r) & Oh Scaffold 47,978 & $5^{\prime}-$ TCC ATg TgT AgA gAT CAA ACA Cg -3' $(43,66)$ \\
\hline OhSSP2-ex2-R (r) & Oh Scaffold 4527 & 5' - CTC AgC TTC AAA gAg CCC TCT -3' $(52,64)$ \\
\hline OhSSP2-F (f) & Oh Scaffold 4527 & $5^{\prime}$ - gAg CAT gCT ATA gAg ggC TCT -3' $(52,64)$ \\
\hline OhSSP2-R (r) & Oh Scaffold 4527 & $5^{\prime}$ - gAT CAA ACA TCA CAg CgC TgC - $3^{\prime}(52,64)$ \\
\hline OhSSP1-ex2-R (r) & Oh Scaffold 4527 & $5^{\prime}$ - TTA Agg AAC ACT CCA AAg CAC C -3' $(52,64)$ \\
\hline OhSSP1-F (f) & Oh Scaffold 4527 & $5^{\prime}$ - gAg ggT gCT TTg gAg TgT TCC -3' $(45,64)$ \\
\hline OhSSP1-R (r) & Oh Scaffold 4527 & $5^{\prime}$ - gAT CAg ACA CCA CAg CTg Tgg -3' $(57,66)$ \\
\hline OhSSP6-ex2-R (r) & Oh Scaffold 10,541 & $5^{\prime}$ - TAA ACT gAg gTT TAA AgA gAT CCA -3' $(33,64)$ \\
\hline OhSSP6-F (f) & Oh Scaffold 10,541 & $5^{\prime}$ - gCA gCA TgC TTC ATg gAT CTC -3' $(52,64)$ \\
\hline OhSSP6-R (r) & Oh Scaffold 12,359 & $5^{\prime}$ - CCg TgT gAA AAg NTC AgA CAT C -3' $(50,66)$ \\
\hline
\end{tabular}

With regard to PmSSP-4, the sense primer, PmSSP34-5UTR, described above, and the antisense primer PmSSP4ex2-R, 5'-CgT TTC Agg TAA Agg AAT ACT C-3', which anneals to the second exon of PmSSP-4 based on the nucleotide sequence of $P m$ Scaffold 21,362, were used to amplify the 1139 bp $5^{\prime}$ portion of PmSSP-4 (Table 15). Using Pm Scaffold 21,362, the sense primer, PmSSP4-F, 5'-gAg TAT TCC TTT ACC TgA AAC g- $3^{\prime}$, which anneals to the middle portion of the second exon of PmSSP-4, and the antisense primer, PmSSP34-R, described above, were then used to amplify the 2999 bp $3^{\prime}$ segment of PmSSP-4. The 5' segment of PmSSP-4 overlapped with the $3^{\prime}$ segment of PmSSP-4 by 22 bp (Table 15). The physical structure of the $4118 \mathrm{bp}$ segment encompassing the first exon of PmSSP-4 to the $311 \mathrm{bp}$ at the $3^{\prime}$ region downstream of the fourth exon of $P m S S P-4$ was sequenced.

For OhSSP-5 $\alpha$ (Oh Scaffold 4527), the sense primer, OhSSPs-5UTR, 5'-ATA AAT Tgg Agg AgC RgA TTC CT-3', which anneals to the common nucleotide sequence of the $5^{\prime}$ UTR of OhSSPs, and the antisense primer, OhSSP5-ex2-R, 5'-CTC AgC TTC AAA gCC CCA gg-3', which anneals to the second exon of OhSSP-5, were used to amplify the $1107 \mathrm{bp} 5^{\prime}$ segment of OhSSP-5 $\alpha$ (Table 15). The sense primer OhSSP5-F, 5' -gAg CAT gCT TTA CCT ggg gC-3', which anneals to the middle portion of the second exon of OhSSP-5 $\alpha$ (Oh Scaffold 4527), and the antisense primer, OhSSP5-R 5'-TCC ATg TgT AgA gAT CAA ACA Cg-3', which anneals to the middle portion of the fourth exon of OhSSP-5 $\alpha$ (Oh Scaffold 47,978), were the used to amplify the $2130 \mathrm{bp} 3^{\prime}$ part of OhSSP-5 $\alpha$ (Table 15). The $5^{\prime}$ segment of OhSSP-5 $\alpha$ overlapped with the $3^{\prime}$ segment of OhSSP- $5 \alpha$ by $32 \mathrm{bp}$. The sequence of the 3205 bp segment encompassing the first exon of OhSSP-5 $\alpha$ to the fourth exon of OhSPP-5 $\alpha$ was determined.

In regard to OhSSP-5 $\beta$, the sense primer, OhSSPs-5UTR, described above, and the antisense primer, OhSSP2-ex2-R, 5' -CTC AgC TTC AAA gAg CCC TCT-3', which anneals to the second exon of OhSSP-5 $\beta$ (Oh Scaffold 4527), were used to amplify the 2456 bp $5^{\prime}$ section of OhSSP-5 $\beta$ (Table 15). The sense primer, OhSSP2-F, 5' -gAg CAT gCT ATA gAg ggC TCT-3', which anneals to the middle portion of the second exon of OhSSP-5 $\beta$, and the antisense primer, OhSSP2-R, 5' -gAT CAA ACA TCA 
CAg CgC TgC- $3^{\prime}$, which anneals to the fourth exon of OhSSP-5 $\beta$, were then used to amplify the 2180

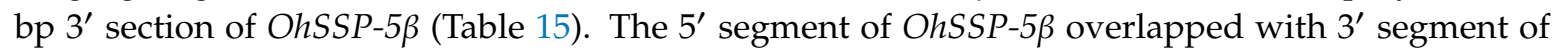
OhSSP-5 $\beta$ by $42 \mathrm{bp}$. The $4594 \mathrm{bp}$ segment encompassing the first exon of OhSSP-5 $\beta$ to the fourth exon of OhSPP-5 $\beta$ was sequenced.

For OhSSP-5 $\gamma$, the sense primer, OhSSPs-5UTR, described above, and the antisense primer, OhSSP1-ex2-R, 5'-TTA Agg AAC ACT CCA AAg CAC C-3', which anneals to the second exon of

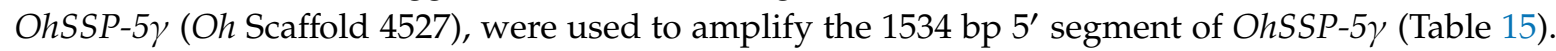
The sense primer, OhSSP1-F, 5'-gAg ggT gCT TTg gAg TgT TCC-3', which anneals to the middle portion of the second exon of OhSSP-5 $\gamma$ (Oh Scaffold 4527), and the antisense primer, OhSSP1-R, $5^{\prime}$-gAT CAg ACA CCA CAg CTg Tgg- $3^{\prime}$, which anneals to the fourth exon of OhSSP-5 $\gamma$, were then used to amplify the $1999 \mathrm{bp} 3^{\prime}$ segment of OhSSP-5 $\gamma$. The $5^{\prime}$ half segment of OhSSP-5 $\gamma$ overlapped with the $3^{\prime}$ half segment of OhSSP-5 $\gamma$ by $26 \mathrm{bp}$ (Table 15). The structure of the $3508 \mathrm{bp}$ segment encompassing the first exon of OhSSP-5 $\gamma$ to the fourth exon of OhSPP-5 $\gamma$ was deciphered.

For OhSSP-6, the sense primer, OhSSPs-5UTR, described above, and the antisense primer, OhSSP6-ex2-R, 5'-TAA ACT gAg gTT TAA AgA gAT CCA-3', which anneals to the second exon of OhSSP-6 (Oh Scaffold 10,541), were used to amplify the 1734 bp 5' segment of OhSSP-6 (Table 15). The sense primer, OhSSP6-F, $5^{\prime}$-gCA gCA TgC TTC ATg gAT CTC-3', which anneals to the middle portion of the second exon of OhSSP-6 (Oh Scaffold 10,541), and the antisense primer, OhSSP6-R, $5^{\prime}$-CCg TgT gAA AAg NTC AgA CAT C-3', which anneals to the fourth exon of OhSSP-6 (Oh Scaffold 12,359), were then used to amplify the $3461 \mathrm{bp} 3^{\prime}$ segment of OhSSP-6 (Table 15). The $5^{\prime}$ section of OhSSP- 6 overlapped with the $3^{\prime}$ segment of OhSSP- 6 by $43 \mathrm{bp}$. The sequence of the $5152 \mathrm{bp}$ segment encompassing the first exon of OhSSP-6 to the fourth exon of OhSPP- 6 was determined. Nucleotide sequences of OhSSP-6, OhSSP- $5 \alpha$, OhSSP-5 $\beta$, OhSSP- $5 \gamma, P m S S P-4$, and PmSSP-3 are available in the Genbank/EMBL/DDBJ databases under Accession Nos. LC518074-LC518078 and LC519888.

\subsection{Expression Analysis of PfSSP-6 mRNA Using Semi-Quantitative RT-PCR}

First-strand cDNAs from snake organs were synthesized by reverse transcription and primer extension with a SMART cDNA Library Construction Kit (Clontech, California, USA). Based on nucleotide sequences of the genes encoding PfSSP-6, the sense primer SSP6-5UTR-1, described above, and the antisense primer SSP6-3UTR-2, 5' - ACA TgA gAg ATT TAT TCC AgT gTg - $3^{\prime}$, which anneals to the $3^{\prime}$ terminal of the fourth exon of PfSSP-6, were designed (Table 14). cDNA of $\beta$-actin, designated as ACTB, was amplified as an internal standard with the sense primer, SHU7, 5'-CAg AgC AAg AgA ggT ATC CN-3' $(\mathrm{N}=\mathrm{G}, \mathrm{A}, \mathrm{T}, \mathrm{C})$, and the antisense primer, SHU8, 5'-TAg ATg ggC ACA gTg Tgg $\mathrm{gN}-3^{\prime}$, as described previously [54].

\subsection{Mathematical Analysis}

Alignment of the amino acid sequences of snake SSPs was performed using ClustalX software. Nucleotide sequences of ORFs encoding the mature SSPs were rearranged and gaps in the aligned amino acid sequences were removed using PAL2NAL. The rates of synonymous $\left(K_{\mathrm{S}}\right)$ and nonsynonymous $\left(K_{\mathrm{A}}\right)$ substitutions per site between the ORFs of the genes were calculated using the Nei-Gojobori method, as implemented in PAML [55]. After removing LINEs, DNA transposons, and indels (insertion/deletion) from the introns, alignment of introns was performed using ClustalX. Values of $K_{\mathrm{N}}$ that estimated rates of substituted nucleotides between the introns of SSPs were calculated from the aligned sequence data.

Author Contributions: K.I. and T.C. designed experiments and performed analyses. K.I., A.T., M.M., H.S., Y.F., S.H., N.O.-U., M.O., and T.C. prepared materials from live specimen. K.I. performed sequencing and manual assembly from PfSSP-6 to PfSSP-4. T.C. supervised the project. K.I. and T.C. wrote the manuscript with contributions from all other authors. All authors have read and agreed to the published version of the manuscript.

Funding: This work was partially supported by the Ministry of Education, Science, Sports and Culture, Grant-in Aid for Scientific Research (C), 2014-2016 (26340095, Takahito Chijiwa).

Conflicts of Interest: The authors declare no conflicts of interest. 


\section{References}

1. Aird, S.D.; Watanabe, Y.; Villar-Briones, A.; Roy, M.C.; Terada, K.; Mikheyev, A.S. Quantitative high-throughput profiling of snake venom gland transcriptomes and proteomes (Ovophis okinavensis and Protobothrops flavoviridis). BMC Genomics 2013, 14, 790. [CrossRef] [PubMed]

2. Rodrigues, R.S.; Boldrini-França, J.; Fonseca, F.P.P.; de la Torre, P.; Henrique-Silva, F.; Sanz, L.; Calvete, J.J.; Rodrigues, V.M. Combined snake venomics and venom gland transcriptomic analysis of Bothropoides pauloensis. J. Proteomics 2012, 75, 2707-2720. [CrossRef] [PubMed]

3. Rokyta, D.R.; Wray, K.P.; Margres, M.J. The genesis of an exceptionally lethal venom in the timber rattlesnake (Crotalus horridus) revealed through comparative venom-gland transcriptomics. BMC Genomics 2013, 14, 394. [CrossRef] [PubMed]

4. Brunie, S.; Bolin, J.; Gewirth, D.; Sigler, P.B. The refined crystal structure of dimeric phospholipase $\mathrm{A}_{2}$ at 2.5 A Access to a shielded catalytic center. J. Biol. Chem. 1985, 260, 9742-9749. [PubMed]

5. Holland, D.R.; Clancy, L.L.; Muchmore, S.W.; Ryde, T.J.; Einspahr, H.M.; Finzel, R.L.; Heinrikson, R.L.; Watenpaugh, K.D. The crystal structure of a lysine 49 phospholipase $\mathrm{A}_{2}$ from the venom of the cottonmouth snake at 2.0-Å resolution. J. Biol. Chem. 1990, 265, 17649-17656.

6. Renetseder, R.; Brunie, S.; Dijkstra, B.W.; Drenth, J.; Sigler, P.B. A comparison of the crystal structures of phospholipase $A_{2}$ from bovine pancreas and Crotalus atrox venom. J. Biol. Chem. 1985, 260, 11627-11634.

7. Suzuki, A.; Matsueda, E.; Yamane, T.; Ashida, T.; Kihara, H.; Ohno, M. Crystal Structure Analysis of Phospholijase $\mathrm{A}_{2}$ from Trimeresurus flavoviridis (Habu Snake) Venom at 1.5 Å Resolution. J. Biochem. 1995, 117, 730-740. [CrossRef]

8. Fox, J.W.; Serrano, S.M. Structural considerations of the snake venom metalloproteinases, key members of the M12 reprolysin family of metalloproteinases. Toxicon 2005, 45, 969-985. [CrossRef]

9. Omori-Satoh, T.; Sadahiro, S. Resolution of the major hemorrhagic component of Trimeresurus flavoviridis venom into two parts. Biochim. Biophys. Acta 1979, 580, 392-404. [CrossRef]

10. Kini, R.M. Excitement ahead: Structure, function and mechanism of snake venom phospholipase $\mathrm{A}_{2}$ enzymes. Toxicon 2003, 42, 827-840. [CrossRef]

11. Masuda, S.; Hayashi, H.; Atobe, H.; Morita, T.; Araki, S. Purification, cDNA cloning and characterization of the vascular apoptosis-inducing protein, HV1, from Trimeresurus flavoviridis. J. Biochem. 2001, 268, 3339-3345. [CrossRef]

12. Matsui, T.; Fujimura, Y.; Titani, K. Snake venom proteases affecting hemostasis and thrombosis. Biochim. Biophys. Acta 2000, 1447, 146-156. [CrossRef]

13. Carone, S.E.I.; Menaldo, D.L.; Sartim, M.A.; Bernardes, C.P.; Caetano, R.C.; da Silva, R.R.; Cabral, H.; Barraviera, B.; Ferreira Junior, R.S.; Sampaio, S.V. BjSP, a novel serine protease from Bothrops jararaca snake venom that degrades fibrinogen without forming fibrin clots. Toxicol. Appl. Pharmacol. 2018, 357, 50-61. [CrossRef] [PubMed]

14. Kini, R.M. Venom Phospholipase $A_{2}$ Enzymes: Structure, Function and Mechanism; Kini, R.M., Ed.; John Wiley \& Sons: Hoboken, NJ, USA, 1997.

15. Kihara, H.; Uchikawa, R.; Hattori, S.; Ohno, M. Myotoxicity and physiological effects of three Trimeresurus flavoviridis phospholipases $\mathrm{A}_{2}$. Biochem. Int. 1992, 28, 895-903. [PubMed]

16. Oda, N.; Ogawa, T.; Ohno, M.; Sasaki, H.; Sakaki, Y.; Kihara, H. Cloning and Sequence Analysis of cDNA for Trimeresurus flavoviridis Phospholipase $\mathrm{A}_{2}$, and Consequent Revision of the Amino Acid Sequence. J. Biochem. 1990, 108, 816-821. [CrossRef]

17. Yamaguchi, Y.; Shimohigashi, Y.; Chijiwa, T.; Nakai, M.; Ogawa, T.; Hattori, S.; Ohno, M. Characterization, amino acid sequence and evolution of edema-inducing, basic phospholipase $\mathrm{A}_{2}$ from Trimeresurus flavoviridis venom. Toxicon 2001, 39, 1069-1076. [CrossRef]

18. Posada Arias, S.; Rey-Suárez, P.; Pereáñez, J.A.; Acosta, C.; Rojas, M.; Delazari dos Santos, L.; Ferreira, R.S., Jr.; Núñez, V. Isolation and Functional Characterization of an Acidic Myotoxic Phospholipase A2 from Colombian Bothrops asper Venom. Toxins 2017, 9, 342. [CrossRef] [PubMed]

19. Chijiwa, T.; Hamai, S.; Tsubouchi, S.; Ogawa, T.; Deshimaru, M.; Oda-Ueda, N.; Hattori, S.; Kihara, H.; Tsunasawa, S.; Ohno, M. Interisland Mutation of a Novel Phospholipase $\mathrm{A}_{2}$ from Trimeresurus flavoviridis Venom and Evolution of Crotalinae Group II Phospholipases A2. J. Mol. Evol. 2003, 57, 546-554. [CrossRef] 
20. Liu, S.Y.; Yoshizumi, K.; Oda, N.; Ohno, M.; Tokunaga, F.; Iwanaga, S.; Kihara, H. Purification and Amino Acid Sequence of Basic Protein II, a Lysine-49-Phospholipase $\mathrm{A}_{2}$ with Low Activity, from Trimeresurus flavoviridis Venom. J. Biochem. 1990, 107, 400-408. [CrossRef]

21. Yoshizumi, K.; Liu, S.Y.; Miyata, T.; Saita, S.; Ohno, M.; Iwanaga, S.; Kihara, H. Purification and amino acid sequence of basic protein I, a lysine-49-phospholipase $\mathrm{A}_{2}$ with low activity, from the venom of Trimeresurus flavoviridis (Habu snake). Toxicon 1990, 28, 43-54. [CrossRef]

22. Teixera, L.F.; de Carvalho, L.H.; de Castro, O.B.; Bastos, J.F.S.; Néry, N.M.; Oliveira, G.A.; Kayano, A.M.; Soares, A.M.; Zuliani, J.P. Local and systemic effects of BdipTX-I, a Lys-49 phospholipase A2 isolated from Bothrops diporus snake venom. Toxicon 2018, 141, 55-64. [CrossRef] [PubMed]

23. Nobuhisa, I.; Deshimaru, M.; Chijiwa, T.; Nakashima, K.; Ogawa, T.; Shimohigashi, Y.; Fukumaki, Y.; Hattori, S.; Kihara, H.; Ohno, M. Structures of genes encoding phospholipase $\mathrm{A}_{2}$ inhibitors from the serum of Trimeresurus flavoviridis snake. Gene 1997, 191, 31-37. [CrossRef]

24. So, S.; Chijiwa, T.; Ikeda, N.; Nobuhisa, I.; Oda-Ueda, N.; Hattori, S.; Ohno, M. Identification of the B Subtype of $\gamma$-Phospholipase $\mathrm{A}_{2}$ Inhibitor from Protobothrops flavoviridis Serum and Molecular Evolution of Snake Serum Phospholipase $\mathrm{A}_{2}$ Inhibitors. J. Mol. Evol. 2008, 66, 298-307. [CrossRef] [PubMed]

25. Gimenes, S.N.C.; Ferreira, F.B.; Silveira, A.N.P.; Rodrigues, R.S.; Yoneyama, K.A.G.; Izabel dos Santos, J.; Fontes, M.R.d.M.; de Campos Brites, V.L.; Santos, A.L.Q.; Borges, M.H.; et al. Isolation and biochemical characterization of a $\gamma$-type phospholipase A2 inhibitor from Crotalus durissus collilineatus snake serum. Toxicon 2014, 81, 58-66. [CrossRef] [PubMed]

26. Oliveira, C.Z.; Santos-Filho, N.A.; Menaldo, D.L.; Boldrini-Franca, J.; Giglio, J.R.; Calderon, L.A.; Stabeli, R.G.; Rodrigues, F.H.S.; Tasic, L.; da Silva, S.L.; et al. Structural and Functional Characterization of a $\gamma$-Type Phospholipase A2 Inhibitor from Bothrops jararacussu Snake Plasma. Curr. Top. Med. Chem. 2011, 11, 2509-2519. [CrossRef]

27. Serino-Silva, C.; Morais-Zani, K.; Toyama, M.H.; Toyama, D.d.O.; Gaeta, H.H.; Rodrigues, C.F.B.; Aguiar, W.d.S.; Tashima, A.K.; Grego, K.F.; Tanaka-Azevedo, A.M. Purification and characterization of the first $\gamma$-phospholipase inhibitor ( $\gamma$ PLI) from Bothrops jararaca snake serum. PLoS ONE 2018, 13, e0193105. [CrossRef]

28. Yamakawa, Y.; Omori-Satoh, T. Primary Structure of the Antihemorrhagic Factor in Serum of the Japanese Habu: A Snake Venom Metalloproteinase Inhibitor with a Double-Headed Cystatin Domain. J. Biochem. 1992, 112, 583-589. [CrossRef]

29. Deshimaru, M.; Tanaka, C.; Tokunaga, A.; Goto, M.; Terada, S. Efficient Purification of an Antihemorrhagic Factor (HSF) in Serum of Japanese Habu (Trimeresurus flavoviridis). Fukuoka Univ. Sci. Rep. 2003, 33, 45-53.

30. Aoki, N.; Sakiyama, A.; Deshimaru, M.; Terada, S. Identification of novel serum proteins in a Japanese viper: Homologs of mammalian PSP94. Biochem. Biophys. Res. Commun. 2007, 359, 330-334. [CrossRef]

31. Aoki, N.; Matsuo, H.; Deshimaru, M.; Terada, S. Accelerated evolution of small serum proteins (SSPs)-The PSP94 family proteins in a Japanese viper. Gene 2008, 426, 7-14. [CrossRef]

32. Shioi, N.; Narazaki, M.; Terada, S. Novel function of antihemorrhagic factor HSF as an SSP-binding protein in Habu (Trimeresurus flavoviridis) serum. Fukuoka Univ. Sci. Rep. 2011, 41, 177-184.

33. Aoki, N.; Sakiyama, A.; Kuroki, K.; Maenaka, K.; Kohda, D.; Deshimaru, M.; Terada, S. Serotriflin, a CRISP family protein with binding affinity for small serum protein-2 in snake serum. Biochim. Biophys. Acta 2008, 1784, 621-628. [CrossRef] [PubMed]

34. Yamazaki, Y.; Koike, H.; Sugiyama, Y.; Motoyoshi, K.; Wada, T.; Hishinuma, S.; Mita, M.; Morita, T. Cloning and characterization of novel snake venom proteins that block smooth muscle contraction. Eur. J. Biochem. 2002, 269, 2708-2715. [CrossRef] [PubMed]

35. Shioi, N.; Ogawa, E.; Mizukami, Y.; Abe, S.; Hayashi, R.; Terada, S. Small serum protein-1 changes the susceptibility of an apoptosis-inducing metalloproteinase HV1 to a metalloproteinase inhibitor in habu snake (Trimeresurus flavoviridis). J. Biochem. 2013, 153, 121-129. [CrossRef]

36. Shioi, N.; Nishijima, A.; Terada, S. Flavorase, a novel non-haemorrhagic metalloproteinase in Protobothrops flavoviridis venom, is a target molecule of small serum protein-3. J. Biochem. 2015, 158, 37-48. [CrossRef] [PubMed]

37. Chijiwa, T.; So, S.; Hattori, S.; Yoshida, A.; Oda-Ueda, N.; Ohno, M. Suppression of severe lesions, myonecrosis and hemorrhage, caused by Protobothrops flavoviridis venom with its serum proteins. Toxicon 2013, 76, 197-205. [CrossRef] 
38. Tanaka, Y.; Shioi, N.; Terada, S.; Deshimaru, M. Structural Organization and Evolution of a Cluster of Small Serum Protein Genes of Protobothrops Flavoviridis Snake. Fukuoka Univ. Sci. Rep. 2013, 43, 59-66.

39. Chijiwa, T.; Inamaru, K.; Takeuchi, A.; Maeda, M.; Yamaguchi, K.; Shibata, H.; Hattori, S.; Oda-Ueda, N.; Ohno, M. Unique structure (construction and configuration) and evolution of the array of small serum protein genes of Protobothrops flavoviridis snake. Biosci. Rep. 2019, 39, BSR20190560. [CrossRef]

40. Shibata, H.; Chijiwa, T.; Oda-Ueda, N.; Nakamura, H.; Yamaguchi, K.; Hattori, S.; Matsubara, K.; Matsuda, Y.; Yamashita, A.; Isomoto, A.; et al. The habu genome reveals accelerated evolution of venom protein genes. Sci. Rep. 2018, 8, 1-11. [CrossRef]

41. Ito, Y.; Tsuda, R.; Kimura, H. Ultrastructural localizations of beta-microseminoprotein, a prostate-specific antigen, in human prostate and sperm: Comparison with gamma-seminoprotein, another prostate-specific antigen. J. Lab. Clin. Med. 1989, 114, 272-277.

42. Haas, N.B.; Grabowski, J.M.; Sivitz, A.B.; Burch, J.B. Chicken repeat 1 (CR1) elements, which define an ancient family of vertebrate non-LTR retrotransposons, contain two closely spaced open reading frames. Gene 1997, 197, 305-309. [CrossRef]

43. Kajikawa, M.; Ohshima, K.; Okada, N. Determination of the entire sequence of turtle CR1: The first open reading frame of the turtle CR1 element encodes a protein with a novel zinc finger motif. Mol. Biol. Evol. 1997, 14, 1206-1217. [CrossRef] [PubMed]

44. Blin, N.; Stafford, D.W. A general method for isolation of high molecular weight DNA from eukaryotes. Nucleic Acids Res. 1976, 3, 2023-2308. [CrossRef] [PubMed]

45. Smit, A.; Hubley, R.; Green, P. RepeatMasker-Open-3.0 [WWW Document] RepeatMasker-Open3.0. 1996. Available online: http://repeatmasker.org (accessed on 12 March 2018).

46. Benon, G. Tandem repeats finder: A program to analyze DNA sequences. Nucleic Acids Res. 1999, 27, 573-580. [CrossRef]

47. Pasquesi, G.I.M.; Adams, R.H.; Card, D.C.; Schield, D.R.; Corbin, A.B.; Perry, B.W.; Reyes-Velasco, J.; Ruggiero, R.P.; Vandewege, M.W.; Shortt, J.A.; et al. Squamate reptiles challenge paradigms of genomic repeat element evolution set by birds and mammals. Nat. Commun. 2018, 9, 1-11. [CrossRef]

48. Yin, W.; Wang, Z.; Li, Q.; Lian, J.; Zhou, Y.; Lu, B.; Jin, L.; Qiu, P.; Zhang, P.; Zhu, W.; et al. Evolutionary trajectories of snake genes and genomes revealed by comparative analyses of five-pacer viper. Nat. Commun. 2016, 7, 1-11. [CrossRef]

49. Vonk, F.J.; Casewell, N.R.; Henkel, C.V.; Heimberg, A.M.; Jansen, H.J.; McCleary, R.J.; Kerkkamp, H.M.; Vos, R.A.; Guerreiro, I.; Calvete, J.J.; et al. The king cobra genome reveals dynamic gene evolution and adaptation in the snake venom system. Proc. Natl. Acad. Sci. USA 2013, 110, 20651-20656. [CrossRef]

50. Castoe, T.A.; de Koning, A.P.; Hall, K.T.; Card, D.C.; Schield, D.R.; Fujita, M.K.; Ruggiero, R.P.; Degner, J.F.; Daza, J.M.; Gu, W.; et al. The Burmese python genome reveals the molecular basis for extreme adaptation in snakes. Proc. Natl. Acad. Sci. USA 2013, 110, 20645-20650. [CrossRef]

51. Aird, S.D.; Arora, J.; Barua, A.; Qiu, L.; Terada, K.; Mikheyev, A.S. Population Genomic Analysis of a Pitviper Reveals Microevolutionary Forces Underlying Venom Chemistry. Genome Biol. Evol. 2017, 9, 2640-2649. [CrossRef]

52. Warren, W.C.; Wilson, R.K. Direct Submission; Genome Institute; Washington University School of Medicine: St. Louis, MO, USA, 2015.

53. Liu, Y.; Hughes, D.; Dinh, H.; Dugan, S.; Jhangiani, S.; Lee, S.; Okwuonu, G.; Santibanez, J.; Bandaranaike, D.; Chao, H.; et al. Direct Submission; Baylor College of Medicine: Houston, TX, USA, 2014.

54. Chijiwa, T.; Nakasone, H.; Irie, S.; Ikeda, N.; Tomoda, K.; Oda-Ueda, N.; Hattori, S.; Ohno, M. Structural characteristics and evolution of the Protobothrops elegans pancreatic phospholipase $\mathrm{A}_{2}$ gene in contrast with those of Protobothrops genus venom phospholipase $A_{2}$ genes. Biosci. Biotechnol. Biochem. 2013, 77, 97-102. [CrossRef]

55. Yang, Z. PAML 4: Phylogenetic Analysis by Maximum Likelihood. Mol. Biol. Evol. 2007, 24, $1586-1591$. [CrossRef] [PubMed]

(C) 2020 by the authors. Licensee MDPI, Basel, Switzerland. This article is an open access article distributed under the terms and conditions of the Creative Commons Attribution (CC BY) license (http://creativecommons.org/licenses/by/4.0/). 